\title{
Chlamydophila psittaci Infection
}

National Cancer Institute

\section{Source}

National Cancer Institute. Chlamydophila psittaci Infection. NCI Thesaurus. Code C44959.

A bacterial infection caused by Chlamydophila psittaci. Humans are infected by handling sick birds. The Chlamydiae cause respiratory infection manifests with fever, malaise, cough, dyspnea, sore throat, photophobia and headaches. 